\title{
Fabrication of Single-Phase NiTi by Combustion Synthesis of Mechanically Activated Powders
}

\author{
S. Mousavi Nasab, ${ }^{1}$ M. Aboutalebi, ${ }^{1}$ S. H. Seyedein, ${ }^{1}$ A. Molavi Kakhki, ${ }^{2}$ and J. Vahdati Khaki ${ }^{3}$ \\ ${ }^{1}$ Centre of Excellence for Advanced Materials \& Processing (CEAMP), Department of Metallurgy and Materials Engineering, \\ Iran University of Science \& Technology, Tehran 16846-13114, Iran \\ ${ }^{2}$ Department of Materials Science \& Engineering, Sharif University of Technology, Tehran 11365-11155, Iran \\ ${ }^{3}$ Department of Materials Science and Engineering, Ferdowsi University of Mashhad, Mashhad 91779-48974, Iran \\ Correspondence should be addressed to S. Mousavi Nasab, saba.mousavi@gmail.com
}

Received 25 November 2012; Accepted 13 December 2012

Academic Editor: Stefano Gialanella

Copyright ( $) 2012$ S. Mousavi Nasab et al. This is an open access article distributed under the Creative Commons Attribution License, which permits unrestricted use, distribution, and reproduction in any medium, provided the original work is properly cited.

\begin{abstract}
Single-phase NiTi was fabricated through the thermal explosion mode of combustion synthesis of mechanically activated powders. Combustion and ignition temperatures of combustion synthesis were investigated in different milling times. In this process, equiatomic powder mixtures of nickel and titanium were activated by planetary ball mill and pressed into disk-shaped pellets then heated in a tube furnace, while temperature-time profile was recorded. X-ray diffraction analysis (XRD) was performed on milled powders as well as synthesized samples. Scanning electron microscopy (SEM) was also used to study the microstructural evolution during milling. The results showed that there was a threshold milling time to obtain single-phase NiTi. It was also seen that the ignition temperature and combustion temperature were reduced significantly by increasing milling time.
\end{abstract}

\section{Introduction}

NiTi alloy combines the characteristics of shape memory effect and superelasticity with excellent corrosion resistance, wear resistance, mechanical properties, and good biocompatibility [1]. They have been practically used for couplings, actuators, and smart materials, as well as external and internal biomedical applications, for example, orthodontic arch wires, catheters, and orthopaedic implants, and in cardiovascular surgery, and so forth [2]. The extent of the shape memory effect and the temperature range over which it is exhibited depend strongly on the composition of the alloy, and in order to realize the maximum benefits of this effect, it is essential to have an alloy of exact stoichiometry and very good homogeneity [3].

Conventionally, NiTi intermetallics are produced by arc or induction melting followed by hot working and forming [2]. Arc melting requires multiple remelts to achieve sufficient homogeneity, while induction melting has the drawback of oxygen contamination [4]. The powder metallurgy technique has also been used for the NiTi fabrication and offers the ability to avoid the problems of casting defects due to segregation and to produce a variety of component shapes while minimizing subsequent machining operations [5]. Among the mentioned techniques, combustion synthesis (CS) has advantages of time and energy savings that make it an attractive alternative to the conventional methods for the production of various classes of materials [6]. Very homogeneous alloys of desirable stoichiometry also can be synthesized by this route, thus eliminating the subsequent thermomechanical processing for homogenization [7]. Moreover the reacted products are purer and have better mechanical properties than those prepared by conventional methods [8].

Several researches have been done on fabricating NiTi via combustion synthesis $[1,2,7]$ through which the obtained products were typically a mixture of several intermetallic phases, that is, $\mathrm{NiTi}, \mathrm{Ti}_{2} \mathrm{Ni}$, and $\mathrm{Ni}_{3} \mathrm{Ti}$. The Gibbs free energies of these phases indicate that the driving force for the formation of $\mathrm{Ti}_{2} \mathrm{Ni}$ and $\mathrm{Ni}_{3} \mathrm{Ti}$ is stronger than that of $\mathrm{NiTi}$. Therefore, even though the formation of NiTi occurs, it is unlikely that these secondary phases of $\mathrm{Ti}_{2} \mathrm{Ni}$ and $\mathrm{Ni}_{3} \mathrm{Ti}$ will 
entirely disappear [9]. Chu et al. [10] have fabricated porous NiTi shape memory alloy with less undesired phases, using the improved self-propagating high-temperature synthesis (SHS) technique by means of providing the higher heat flux density for SHS reactions using the improved ignition technique and adopting the powder compacts with a larger volume-surface area ratio to reduce heat losses. Biswas also prepared single-phase $\mathrm{NiTi}$, using the thermal explosion mode of combustion synthesis in combination with a controlled postreaction heat treatment [11].

Using mechanical activation before combustion synthesis in order to reduce secondary phases has been reported in Ti$\mathrm{Al}$ [12] and Ta-Si [13] systems. However, the method has not been explored much for preparing NiTi in thermal explosion mode of combustion synthesis. In this paper premechanical activation is applied as to eliminate the $\mathrm{Ni}_{3} \mathrm{Ti}$ phase in combustion synthesis of Ni-Ti powder mixture. Moreover the effect of milling time on combustion and ignition temperatures is investigated.

\section{Experimental Procedure}

The starting materials consisted of high-purity powders of nickel $(99.5 \%, 10 \mu \mathrm{m})$ and titanium $(98 \%, 150 \mu \mathrm{m})$ supplied by Merck Co., Germany. Ti and Ni powders were weighed, in a glove box under an argon atmosphere, to have a composition of $\mathrm{Ni}: \mathrm{Ti}=50: 50$ at. $\%$, then comilled inside a planetary ball mill (PM2400) for different times (1, 3, 5, and 10 hours), using steel balls ( $\Phi 8 \mathrm{~mm})$ as milling media while the ball-to-powder weight ratio and the rotational speed were 10:1 and $200 \mathrm{rpm}$, respectively. To prevent powders from oxidation during milling, the vials were filled with high purity argon. Ethanol was used as process control agent (PCA) to reduce agglomeration and cold welding of the particles. In addition to the milled powders, a reference mixture of equiatomic elemental powders mixed for $1 \mathrm{~h}$ in a Turbula apparatus was prepared. As-milled powders were pressed into disk-shaped pellets using a uniaxial load of $350 \mathrm{MPa}$. Thermal explosion of the pellets was carried out in a tube furnace, under floating argon at heating rate of $30^{\circ} \mathrm{C} / \mathrm{min}$. Thermal analysis was carried out using an $\mathrm{S}$ type $(\mathrm{Pt} / \mathrm{Pt}-$ 10Rh) thermocouple which had been embedded during compaction of the samples. The thermocouple output was collected online using a data acquisition system which was connected to a computer. In order to identify the possible reaction steps, one of the reactions was quenched on the basis of time-temperature profile results. X-ray measurements on as-milled and as-synthesized samples as well as on quenched sample were performed in a Philips PW1800 diffractometer ( $\mathrm{Cu} \mathrm{K \alpha}$ radiation: $\lambda=0.154 \mathrm{~nm}$ at $40 \mathrm{kV}$ and $30 \mathrm{~mA}$ ). The microstructural evolutions of the milled powders were analyzed by scanning electron microscopy (SEM) in a Philips MV2300 at an accelerating voltage of $15 \mathrm{kV}$.

\section{Results and Discussion}

3.1. Mechanical Activation. Figure 1 shows the XRD patterns of $50 \mathrm{Ni}-50 \mathrm{Ti}$ powder mixtures, after different milling times.

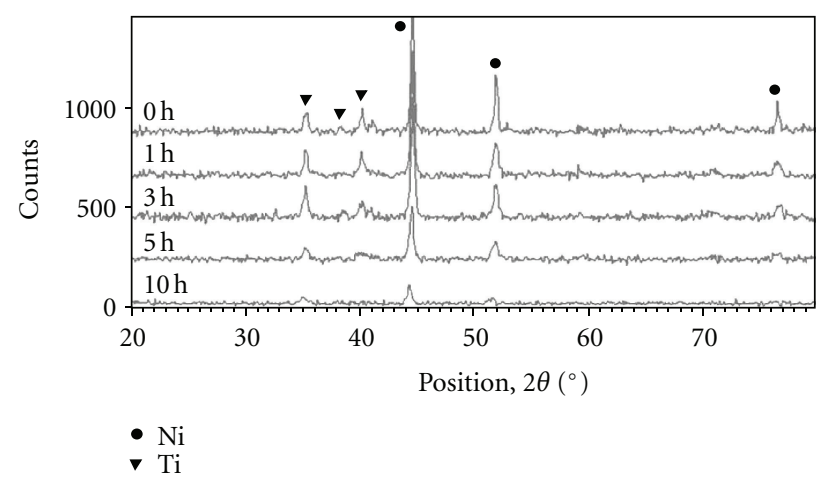

FIGURE 1: XRD patterns of $50 \mathrm{Ni}-50 \mathrm{Ti}$ powder mixtures, after different milling times.

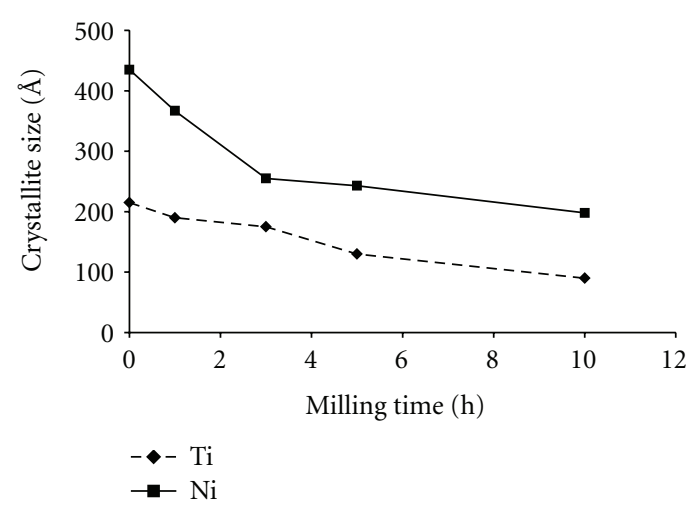

FIGURE 2: Variation of $\mathrm{Ni}$ and Ti crystallite size versus milling time.

As it can be seen in Figure 1, no new phase is formed during milling; that is, the alloying has not occurred. So it is to say that the selected conditions and times of the milling are appropriate in order to mechanically activate the powder mixtures.

$\mathrm{X}$-ray peak broadening with increasing the milling times is also observed in Figure 1, which can be due to instrumental effects, crystallite size, and lattice strain in the material. The crystallite size can be determined by measuring the Bragg peak width at half the maximum intensity and using the Scherrer formula:

$$
d=\frac{0.9 \lambda}{B \cos \theta}
$$

where $d$ is the crystallite size, $\lambda$ is the wavelength of the $\mathrm{X}$ radiation used, $B$ is the peak width at half the maximum intensity, and $\theta$ is the Bragg angle [14]. The calculated crystallite size in different milling times for $\mathrm{Ni}$ and $\mathrm{Ti}$ is shown in Figure 2.

It can be seen that the crystallite size of $\mathrm{Ni}$ and $\mathrm{Ti}$ is decreased with increasing the milling time. Displacement of $\mathrm{Ni}$ X-ray peaks towards lower angles is observed after $3 \mathrm{~h}$ as shown in Figure 3. This indicates that lattice parameter of $\mathrm{Ni}$ increases with milling times due to diffusion of larger atoms of Ti into the Ni lattice resulting in an $\mathrm{Ni}(\mathrm{Ti})$ solid solution. 


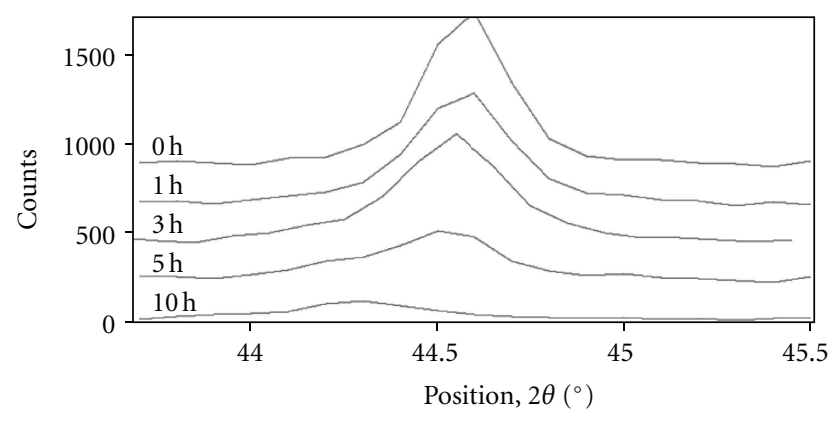

FIGURE 3: Displacement of Ni peak with increasing the milling time.

According to the fact that the Ni lattice parameter increases by $0.1 \%$ per at. $\%$ of dissolved $\mathrm{Ti}$ [15], the dissolution of $\mathrm{Ti}$ in $\mathrm{Ni}$ at different milling times was calculated. Figure 4 shows the lattice parameter of $\mathrm{Ni}$ and the atomic percentage of dissolved $\mathrm{Ti}$ in $\mathrm{Ni}$ lattice versus milling time. Dissolution of $\mathrm{Ti}$ in Ni occurs after $3 \mathrm{~h}$ and increases with increasing milling time as diffusion progresses. Finally after $10 \mathrm{~h}$, the Ni lattice contains 6 at.\% of dissolved Ti which is in agreement with the amount of 6 at.\% reported by Battezzati et al. [16]. It can be seen in Figure 4 that after milling for $5 \mathrm{~h}$, the variation rate of at.\% of dissolved $\mathrm{Ti}$ in $\mathrm{Ni}$ lattice decreases since it almost reaches a saturation level in the stated milling conditions.

$\mathrm{Ni}$-Ti binary system is considered to be a ductile-ductile system. Benjamin and Volin [17] suggested that in the early stages of milling of ductile components, they get flattened to platelet/pancake shapes by a microforging process. These flattened particles then get cold welded together and form a composite lamellar structure of the constituent metals. With increasing milling time, the composite powder particles get work hardened, consequently getting fragmented. The processes of fracturing and welding lead to formation of micrometric agglomerates consisting of nanosized $\mathrm{Ni}$ and $\mathrm{Ti}$ convoluted layers. The progress of changes in microstructure of the Ni-Ti powder mixture during milling for $1 \mathrm{~h}$ and $5 \mathrm{~h}$ is demonstrated by the SEM images in Figures 5 and 6 , respectively.

As it is obvious in Figure 5(a), the powder mixture after milling for $1 \mathrm{~h}$ consists of $20-40 \mu \mathrm{m}$ particles with irregular shapes along with the almost equiaxed 3-5 $\mu \mathrm{m}$ particles. The particle with the lamellar structure which can be seen in Figure 5(b) indicates that the composite particles are formed, in accordance with the milling mechanism, after $1 \mathrm{~h}$ milling. Meanwhile the irregular particle in Figure 5(b) proves the presence of titanium due to its nonlamellar structure as well as its dimension. The presence of $\mathrm{Ti}$ particles in powder mixture after $1 \mathrm{~h}$ milling suggests that only a part of primary $\mathrm{Ni}$ and Ti particles forms composite particles with lamellar structure.

Figure 6(a) shows that formation of micrometric aggregates with a mean size of $20-40 \mu \mathrm{m}$ is registered after $5 \mathrm{~h}$ milling. A more precise observation (Figure 6(b)) reveals the complicated structure of aggregates and the presence of submicron-sized particles. As pointed out earlier, formation

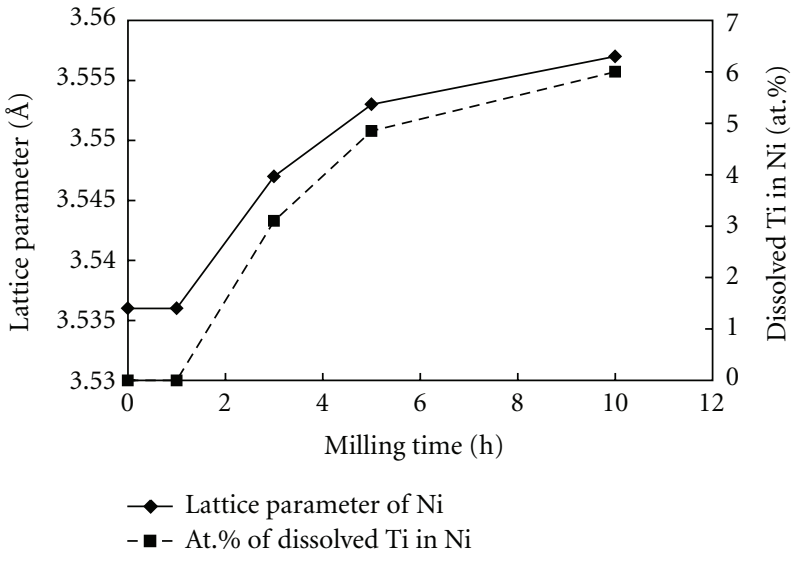

FIGURE 4: Variation of Ni lattice parameter and at.\% of dissolved Ti in Ni lattice versus milling time.

of these micrometric aggregates is typical in the milling of ductile-ductile systems.

3.2. Combustion Synthesis. Figure 7 shows the time-temperature profiles during the heating of powder mixtures which are milled in different times. The intersection of the two slopes leads to the determination of the ignition temperature $\left(T_{\mathrm{ig}}\right)$ [18]. The time-temperature profiles of samples, milled for 0,1 , and $3 \mathrm{~h}$, exhibit two exothermic peaks. The low temperature exotherm which is much smaller and occurred in earlier times could be related to a precombustion reaction. The high temperature exotherm which is much bigger showed the characteristic sharp rise, corresponding to the main combustion reaction.

The XRD pattern of the products obtained after the first exothermic peak of the sample milled for $0 \mathrm{~h}$ is shown in Figure 8.

It could be concluded that the low temperature exotherm is due to the formation of little amounts of NiTi and $\mathrm{Ni}_{4} \mathrm{Ti}_{3}$ phases. The low temperature exotherm related to a precombustion synthesis is not observed in the time-temperature profiles of the samples milled for 5 and $10 \mathrm{~h}$, which is due to the significant decrease in ignition temperature of the main combustion reaction. It is worth noting that the first exothermic peak of the sample milled for $10 \mathrm{~h}$ corresponded to the main combustion reaction since it is sharper and more exothermic than the peaks which were due to the precombustion reactions.

Figure 9 illustrates the variation of ignition and combustion temperature versus milling time. As it can be seen in this figure, $T_{\text {ig }}$ decreases almost 400 degrees with the increase in milling time. Such a decrease can be explained by the changes occurred in milling.

The milling process, which causes the intimate mixing of particles on a nanoscale, leads to the reduction in the crystallite size and accumulation of defects in powder particles, which introduce an additional energy to the reactant system in the form of interfacial energy and strain energy. This effectively lowers the activation barriers for reactions. 

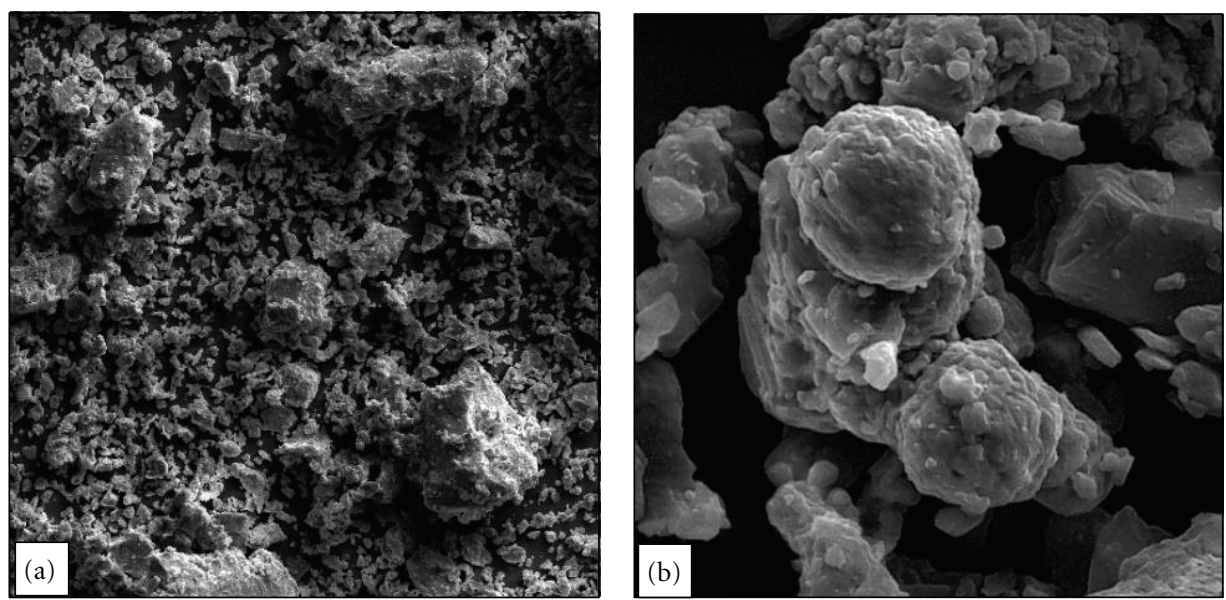

Figure 5: SEM images of the Ni-Ti powder mixture after milling for $1 \mathrm{~h}$ : (a) 1000X, (b) 15000X.
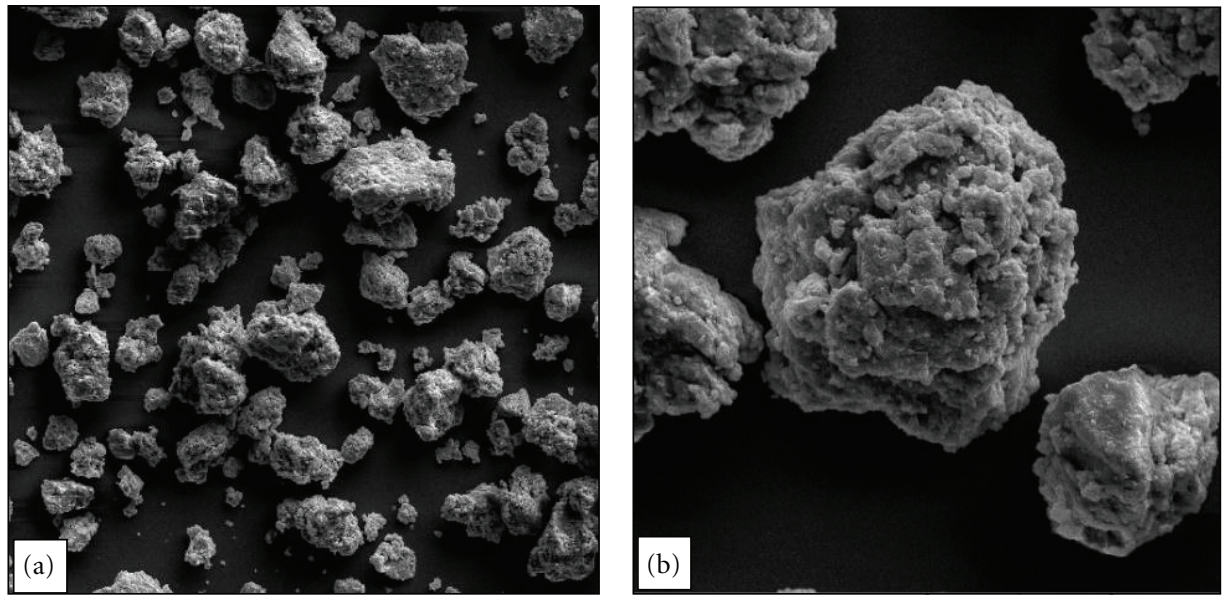

FIGURE 6: SEM images of the Ni-Ti powder mixture after milling for $5 \mathrm{~h}$ : (a) 1000X, (b) 5000X.

Moreover, the presence of a variety of crystal defects (i.e., dislocations, vacancies, staking faults, grain boundaries, etc.) enhances the diffusivity of elements [19]. Further, the formation of micrometric aggregates, consisting of nanosized elemental convoluted layers, decreases the diffusion distances [20].

Decrease in diffusion distances as well as activation barrier to NiTi formation reaction occurred during milling causes the ignition temperature to decrease significantly in postcombustion synthesis. According to Figure 9 it can be concluded that the above milling effects reach a maximum level after $5 \mathrm{~h}$ of milling in the stated conditions which results in keeping $T_{\mathrm{ig}}$ steady by increasing milling time from 5 to $10 \mathrm{~h} \mathrm{[14].}$

In a nonadiabatic condition of a combustion synthesis reaction, the maximum temperature of products is called combustion temperature which is equivalent to the adiabatic temperature. Adiabatic temperature $\left(T_{\mathrm{ad}}\right)$ is mainly dependent on reactants' temperature and reaction enthalpy (2) whereas the latter itself is a function of reactants' temperature. Decreasing in reactants' temperature from $952 \mathrm{~K}$ to $569 \mathrm{~K}$ by increasing the milling time causes the enthalpy of the reaction to change from -71.9 to $-68.3 \mathrm{Kj} / \mathrm{mol}$ which is negligible. According to this slight change in enthalpy, the similar trend of ignition and combustion temperature variations shown in Figure 9 and the relation between $T_{\mathrm{ig}}$ and $T_{\text {ad }}$, that is, $T_{\text {com }}$ presented in (2), it can be concluded that $T_{\text {com }}$ is determined specifically by $T_{\mathrm{ig}}$ :

$$
-\Delta H_{f}^{0}\left(T_{0}\right)=\int_{T_{0}}^{T_{\mathrm{ad}}} C_{p} \text { (products) } d T .
$$

Figure 9 also gives the information that milling, resulting in nonequilibrium condition in powder mixtures, does not change the heat of the formation. This is because the difference between $T_{\mathrm{ig}}$ and $T_{\text {com }}$ which represents the exothermic feature of the reaction remained constant in different milling times. Figure 10 indicates XRD patterns of 


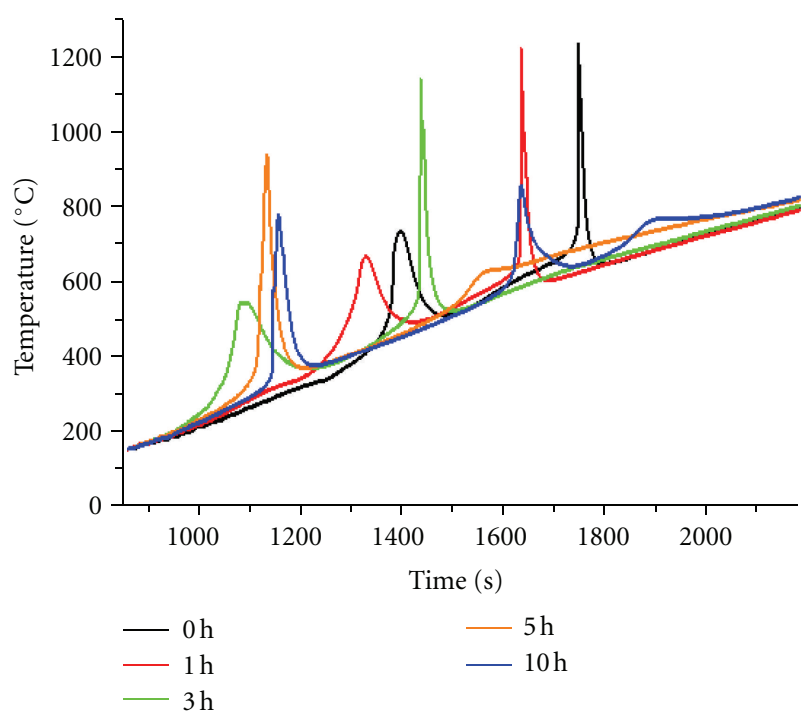

FIGURE 7: Time-temperature profiles of powder mixtures milled in different milling times.

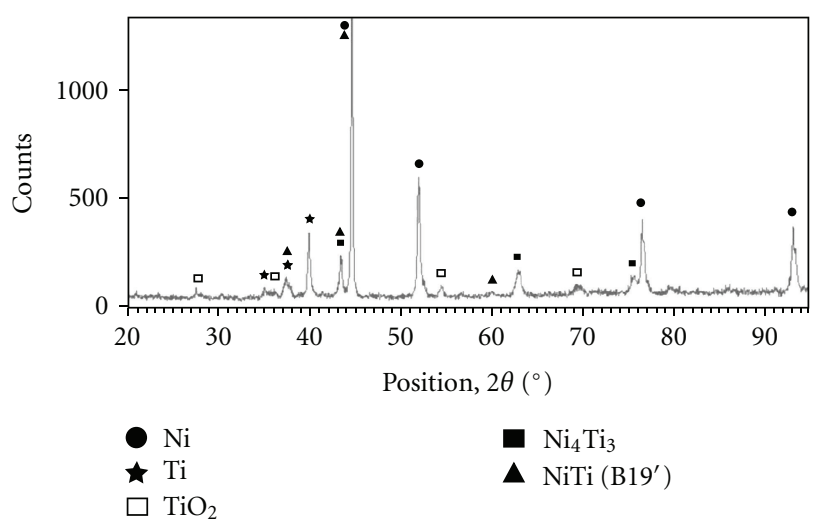

FIGURE 8: The XRD pattern of the products obtained after the first exothermic peak of the sample milled for $0 \mathrm{~h}$.

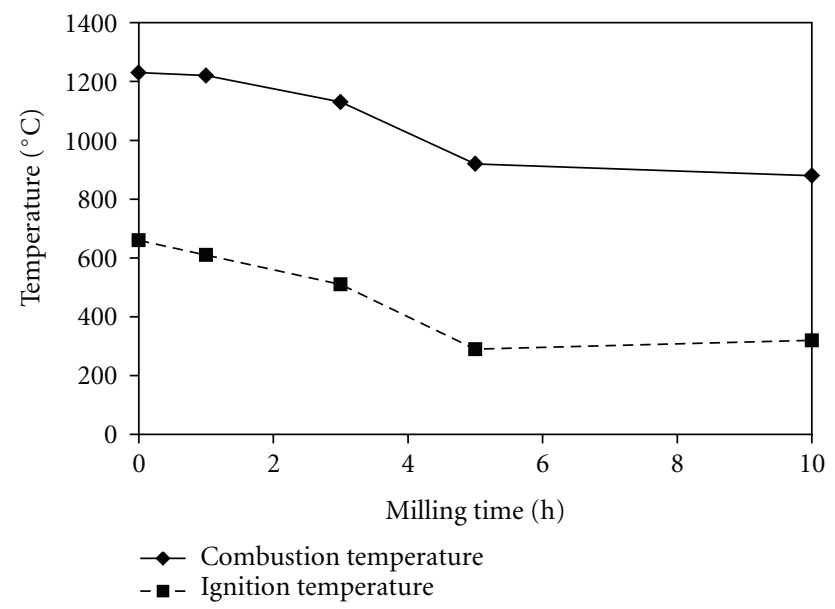

FIGURE 9: Variation of ignition and combustion temperature versus milling time.

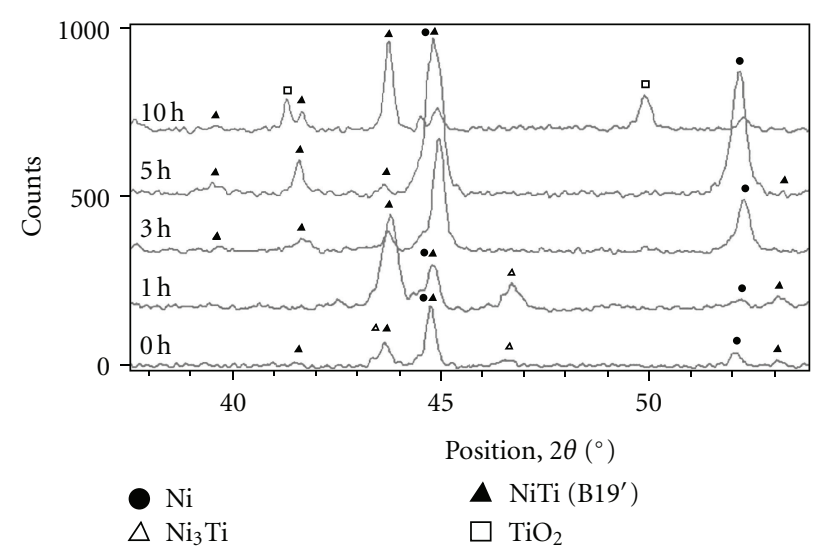

FIGURE 10: XRD patterns of powder mixtures milled in different milling times after combustion synthesis.

powder mixtures milled for different times, after combustion synthesis. As it can be seen, increasing milling time to $3 \mathrm{~h}$ prevents the formation of undesired $\mathrm{Ni}_{3} \mathrm{Ti}$ phase, in the postcombustion synthesis. In order to explain this, it is to be said that milling for $3 \mathrm{~h}$ makes a homogenous powder mixture with less nonstoichiometric zones which reduces the possibility of $\mathrm{Ni}_{3} \mathrm{Ti}$ formation in the postcombustion synthesis.

Moreover, as it can be seen from Figure 4, dissolution of Ti in Ni lattice occurred after $3 \mathrm{~h}$ milling, which creates the zones in powder mixture where the chemical composition is close to NiTi stoichiometry. The formation of such zones enhances the reactivity of $\mathrm{Ni}$ - $\mathrm{Ti}$ system which leads to increase in the probability of NiTi formation [18].

High chemical affinity of titanium with oxygen and high surface energy of the milled titanium powders which enhances the reactivity of Ti caused the formation of little amounts of $\mathrm{TiO}_{2}$, even in a high purity argon atmosphere.

\section{Conclusion}

In this paper mechanically activated powders were used to fabricate NiTi intermetallic compound through combustion synthesis method. The results showed that with premechanical activation at least for 3 hours, NiTi alloy can be fabricated without undesired $\mathrm{Ni}_{3} \mathrm{Ti}$ phase through thermal explosion mode of combustion synthesis. Moreover, decrease in diffusion distances caused by micrometric aggregation formation drastically lowers the ignition temperature and as a result lowers the combustion temperature.

\section{References}

[1] C. L. Chua, C. Y. Chung, P. H. Lin, and S. D. Wang, "Fabrication of porous NiTi shape memory alloy for hard tissue implants by combustion synthesis," Materials Science and Engineering A, vol. 366, no. 1, pp. 114-119, 2004.

[2] C. L. Yeh and W. Y. Sung, "Synthesis of NiTi intermetallics by self-propagating combustion," Journal of Alloys and Compounds, vol. 376, no. 1-2, pp. 79-88, 2004.

[3] G. K. Dey, "Micropyretic synthesis of NiTi in propagation mode," Acta Materialia, vol. 51, no. 9, pp. 2549-2568, 2003. 
[4] H. Funakubo, Shape Memory Alloys, Gorden \& Breach, New York, NY, USA, 1987.

[5] M. Bram, A. Ahmad-Khanlou, A. Heckmann, and B. Fuchs, "Powder metallurgical fabrication processes for NiTi shape memory alloy parts," Materials Science and Engineering A, vol. 337, no. 1-2, pp. 254-263, 2002.

[6] C. Zanotti, P. Giuliani, A. Terrosu, S. Gennari, and F. Maglia, "Porous Ni-Ti ignition and combustion synthesis," Intermetallics, vol. 15, no. 3, pp. 404-412, 2007.

[7] B. Y. Tay, C. W. Goh, Y. W. Gu, and C. S. Lim, "Porous NiTi fabricated by self-propagating high-temperature synthesis of elemental powders," Journal of Materials Processing Technology, vol. 202, no. 1-3, pp. 359-364, 2008.

[8] L. Qiang, Y. Jing-Yuan, M. Bai-Chun, and S. Xu-Dong, "BP neural network prediction of the mechanical properties of porous NiTi shape memory alloy prepared by thermal explosion reaction," Materials Science and Engineering A, vol. 419, no. 1-2, pp. 214-217, 2006.

[9] C. W. Goh, Y. W. Gu, C. S. Lim, and B. Y. Tay, "Influence of nanocrystalline $\mathrm{Ni}$-Ti reaction agent on self-propagating hightemperature synthesized porous NiTi," Intermetallics, vol. 15, no. 4, pp. 461-467, 2007.

[10] C. L. Chu, C. Y. Chung, P. H. Lin, and S. D. Wang, "Fabrication and properties of porous NiTi shape memory alloys for heavy load-bearing medical applications," Journal of Materials Processing Technology, vol. 169, no. 1, pp. 103-107, 2005.

[11] A. Biswas, "Porous NiTi by thermal explosion mode of SHS: processing, mechanism and generation of single phase microstructure," Acta Materialia, vol. 53, no. 5, pp. 1415-1425, 2005.

[12] E. Medda, F. Delogu, and G. Cao, "Combination of mechanochemical activation and self-propagating behaviour for the synthesis of Ti aluminides," Materials Science and Engineering A, vol. 361, no. 1-2, pp. 23-28, 2003.

[13] F. Maglia, C. Milanese, and U. Anselmi-Tamburini, "Combustion synthesis of mechanically activated powders in the Ta-Si system," Journal of Alloys and Compounds, vol. 385, no. 1-2, pp. 269-275, 2004.

[14] C. Suryanarayana, "Mechanical alloying and milling," Progress in Materials Science, vol. 46, no. 1-2, pp. 1-184, 2001.

[15] W. Gu, C. W. Goh, L. S. Goi, C. S. Lim, and A. E. W. Jarfors, "Solid state synthesis of nanocrystalline and/or amorphous 50Ni-50Ti alloy," Materials Science and Engineering A, vol. 392, no. 1-2, pp. 222-228, 2005.

[16] L. Battezzati, G. Cocco, L. Schiffini, and S. Enzo, "Thermal properties of mechanically alloyed Ni50Ti50 powders," Materials Science and Engineering C, vol. 97, pp. 121-124, 1988.

[17] J. S. Benjamin and T. E. Volin, "Mechanism of mechanical alloying," Metallurgical and Materials Transactions, vol. 5, no. 8, pp. 1929-1934, 1974.

[18] C. Gras, E. Gaffet, F. Bernard, and J. C. Niepce, "Enhancement of self-sustaining reaction by mechanical activation: case of an Fe-Si system," Materials Science and Engineering A, vol. 264, no. 1-2, pp. 94-107, 1999.

[19] P. Mossino, "Some aspects in self-propagating high-temperature synthesis," Ceramics International, vol. 30, no. 3, pp. 311-332, 2004.

[20] F. Charlot, E. Gaffet, B. Zeghmati, F. Bernard, and J. C. Niepce, "Mechanically activated synthesis studied by X-ray diffraction in the Fe-Al system ," Materials Science and Engineering A, vol. 262, no. 1-2, pp. 279-288, 1999. 

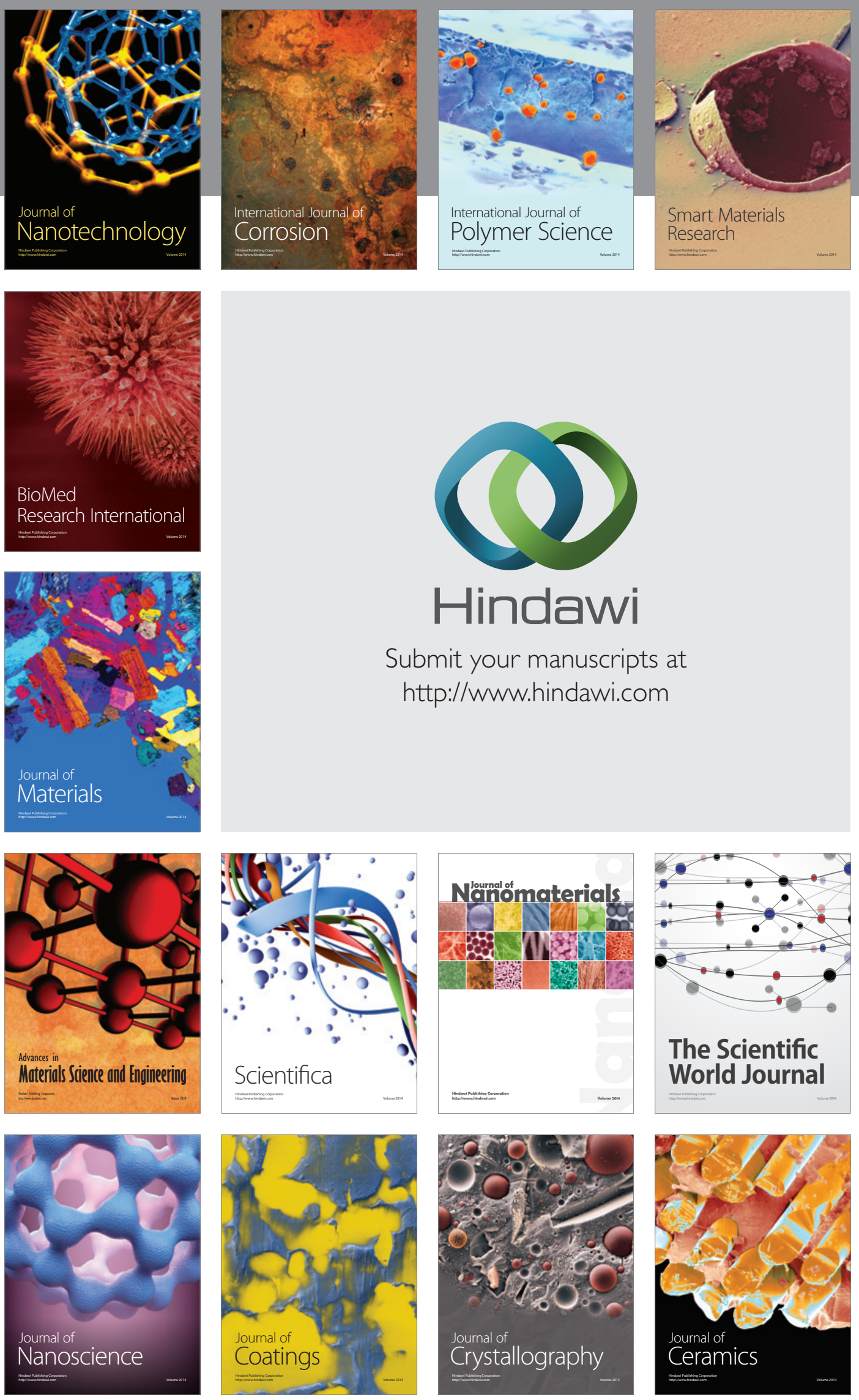

The Scientific World Journal

Submit your manuscripts at

http://www.hindawi.com

\section{World Journal}

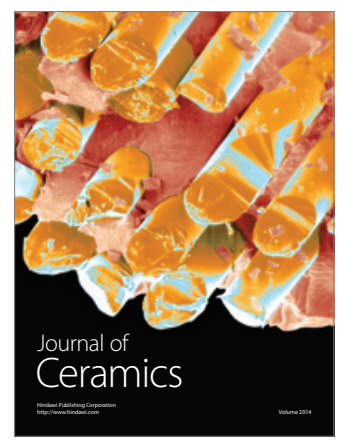

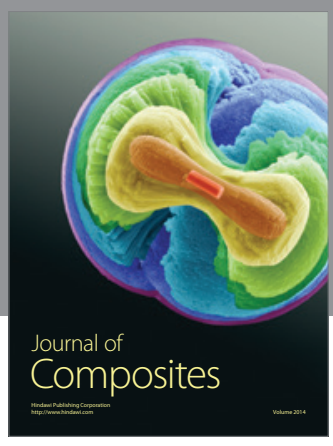
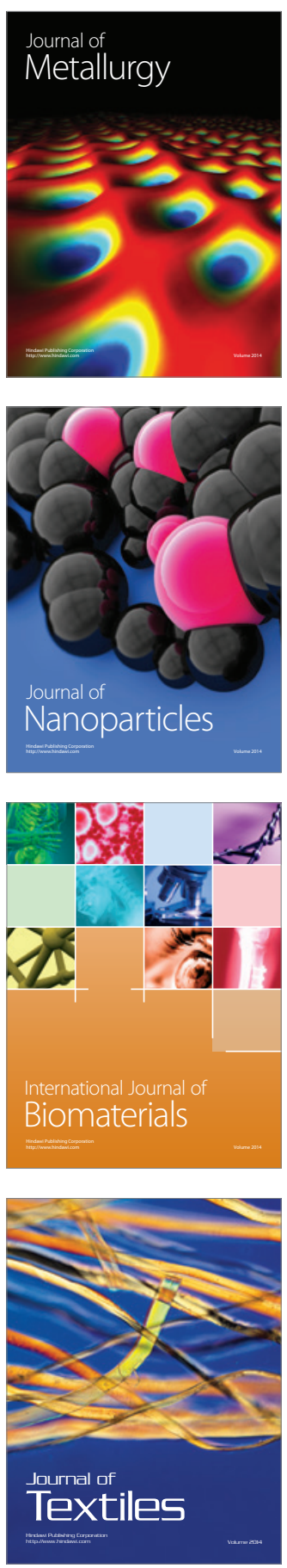